\title{
PARQUE ECOLÓGICO ALDEIA DE CARAPICUÍBA: PROJETO DE PAISAGISMO PARTICIPATIVO VALORIZANDO UM PATRIMÔNIO HISTÓRICO ${ }^{1}$
}

\author{
ECOLOGICAL PARK IN CARAPICUÍBA VILLAGE: LANDSCAPE PARTICIPATIVE \\ DESIGN ENRICHING A HISTORICAL HERITAGE
}

\author{
Sylvia Adriana Dobry-Pronsato* \\ Caio Boucinhas** \\ Antônio Busnardo Filho*** \\ Denise Falcão Pessoa****
}

\begin{abstract}
Parte deste trabalho foi apresentado no XII Congresso Internacional de Reabilitação do Patrimônio Arquitetônico e Edificado - A dimensão cotidiana do patrimônio e desafios para sua preservação: DOBRY-PRONSATO, Sylvia Adriana; BOUCINHAS, Caio; PESSOA, Denise Falcão.

Patrimônio histórico e paisagismo participativo: Aldeia de Carapicuíba e seu entorno - tantos olhares. In: CONGRESSO INTERNACIONAL DE REABILITAÇÃO DO PATRIMÔNIO ARQUITETÔNICO E EDIFICADO, 12, 2014, Bauru, Anais... ISSN/ISBN: 978-85-99679, p. 374-382.
\end{abstract}

\footnotetext{
* Arquiteta e urbanista pela Universidad Nacional de Córdoba (FAU-UNC), Argentina. Mestre e doutora em Arquitetura e Urbanismo pela Faculdade de Arquitetura e Urbanismo da Universidade de São Paulo (FAUUSP). Professora e pesquisadora no Curso de Arquitetura e Urbanismo FIAM-FAAM Centro Universitário do Mestrado Profissional Stricto Sensu na área de Arquitetura e Urbanismo: Projeto, Produção e Gestão do Espaço Urbano. Avenida da Liberdade, 749, $7^{\circ}$ andar, 01502-001, Liberdade, São Paulo, SP, Brasil. sydobry@gmail.com

** Arquiteto e urbanista pela Faculdade de Arquitetura e Urbanismo da Universidade Federal de Minas Gerais (UFMG). Mestre e doutor em Arquitetura e Urbanismo pela Faculdade de Arquitetura e Urbanismo da Universidade de São Paulo (FAUUSP). Professor e pesquisador no Curso de Arquitetura e Urbanismo FIAM-FAAM Centro Universitário do Mestrado Profissional Stricto Sensu na área de Arquitetura e Urbanismo: Projeto, Produção e Gestão do Espaço Urbano. Avenida da Liberdade, 749, $7^{\circ}$ andar, 01502-001, Liberdade, São Paulo, SP, Brasil.

cboucinhas@uol.com.br

*** Arquiteto e urbanista pela Faculdade Farias Brito - Universidade de Guarulhos (UnG). Mestre e doutor pela Faculdade de Educação da Universidade de São Paulo (FEUSP). Professor e pesquisador no Curso de Arquitetura e Urbanismo FIAM FAAM, no Mestrado Profissional Stricto Sensu na área de Arquitetura e Urbanismo: Projeto, Produção e Gestão do Espaço Urbano. Rua Kari, 44, 07047-041, Jardim São João, Guarulhos, SP, Brasil.

antbusnardo@gmail.com

**** Arquiteta e urbanista pela Faculdade de Arquitetura e Urbanismo da Universidade Presbiteriana Mackenzie. Mestre em Arquitetura e Urbanismo, concentração em Desenho Urbano, pelo College of Architecture and Urban Planning - The University of Michigan, USA. Doutora em Arquitetura e Urbanismo pela Faculdade de Arquitetura e Urbanismo da Universidade de São Paulo (FAUUSP). Professora e pesquisadora no Curso de Arquitetura e Urbanismo da Universidade Nove de Julho (Uninove) e Centro Universitário Belas Artes. Rua doutor Louis Couty, 35, ap. 71, 05436-030, Jardim das Bandeiras, São Paulo, SP, Brasil.

denisefpessoa@hotmail.com
} 


\title{
RESUMO
}

Neste artigo discute-se o projeto do Parque Ecológico Aldeia de Carapicuíba, iniciado em 1994 e implantado em 2004. O processo entrelaçou diferentes temas quanto à recuperação e consolidação de sentimentos de pertencimento a um lugar considerado patrimônio histórico e ambiental, e sua valorização. Reflete-se, também, sobre a noção de participação da comunidade, que possibilitou a implantação do parque e facilitou a preservação desse patrimônio histórico e ambiental. $\bigcirc$ método participativo de projetá-lo possibilitou a articulação de diversos níveis de ensino, resultado do trabalho conjunto entre arquiteto contratado pela prefeitura, alunos da pós-graduação da Faculdade de Arquitetura e Urbanismo da Universidade de São Paulo, professores, funcionários e alunos da Escola Estadual de Primeiro Grau Professora Esmeralda Becker Freire de Carvalho, localizada no patrimônio histórico Aldeia de Carapicuíba. Nesse processo, a execução, ainda que parcial em relação ao projeto original, só foi possível pelo envolvimento direto da comunidade, evidenciando que a relação arte-percepção, ao transcender o simples observar, pode contribuir em ações que valorizem o sentimento de pertencimento aos lugares de vida, nesse caso, o patrimônio histórico ambiental. Ao estimular a escola a ocupar os espaços da arte, no desenvolvimento da percepção, abriu-se a probabilidade de maior valorização do patrimônio histórico ambiental e cultural.

Palavras-chave: Parque. Arquitetura e urbanismo. Arte. Percepção e participação. Patrimônio histórico.

\begin{abstract}
This article discusses the design project "Ecological Park in Carapicuiba Village", which was started in 1994 and was implemented in 2004. The process put together different themes such as the recuperation and consolidation of the feeling of belonging to a place considered a historical and environmental patrimony. The study points out the community concept of participation in the design process, considering that, in this case enabled the implementation of the park and strengthened the preservation of the historical and environmental patrimony. The participative method for designing the park enabled the articulation of various levels of teaching, and was accomplished by a team work involving an architect hired by the municipality, graduate students of the FAUUSP (College of Architecture and Urbanism - University of São Paulo) and the staff and high school students of the Esmeralda Becker Freire de Carvalho School, situated in the Carapicuíba historical village. In this process the execution of the original project, even being partial, was only possible because of the community involvement. The participative process also highlights that the relation between art and perception, when goes beyond the simple observation, may contribute to the sense of belonging to a place, and in this case, the preservation of the historical and environmental patrimony. By stimulating the school to occupy the art spaces when developing its perception, it enabled a possibility of a greater valuation of the historical, environmental and cultural patrimony.

Keywords: Park. Architecture and urbanism. Art. Perception and participation. Historical heritage.
\end{abstract}

\section{INTRODUÇÃO}

A proposta do Parque Ecológico Aldeia de Carapicuíba faz parte de um processo iniciado em 1994 pelo arquiteto Caio Boucinhas, contratado pela prefeitura de Carapicuíba para o desenvolvimento do projeto de um parque que incluísse o quadrilátero da Aldeia e seu entorno. Considera-se que um projeto participativo contém a necessidade de assegurar a relação de pertencimento ao lugar, a identidade do usuário e sua inclusão enquanto ser ativo e consciente na cidade. Para isso, é pertinente encontrar metodologias e caminhos. Considerando que um projeto participativo paisagístico pode ser produto de criação coletiva ou individual, dependendo das circunstâncias, 
ambos os casos se relacionam com o fato de que "[...] o problema da arte [...] não é o surgimento do indivíduo, mas o da comunicação". (MERLEAU-PONTY, 1991, p. 85). Assim, ao pensar o projeto de um parque também como processo de arte e tendo a comunicação como dado prioritário, naquela ocasião o arquiteto optou por estabelecer seu escritório na própria Aldeia, entendendo que dessa maneira conseguiria maior inter-relação com a população do lugar, o que the permitiu acessar informações além das que estão nos mapas:

Os meninos utilizam o pátio e seus arredores empinando pipas, jogando pião e bola de gude; os moradores só aos poucos vão confiando, [...] desvendando lugares esquecidos: "aqui tinha uma bica aonde todo mundo vinha buscar água, da boa"; "lá embaixo um lago onde a gente nadava: foram aterrando aos poucos e depois fizeram barracos por cima". [...] íamos descobrindo e catalogando caminhos e trilhas já existentes [...]; o Pico do Jaraguá aparece inteiro a noroeste a partir dos fundos da Igreja, área mal-assombrada, onde existia o cemitério; lá embaixo corre o Anhembi rumo ao Ribeirão Carapicuíba, na divisa com Osasco, afluente do Tietê. Os afluentes do Anhembi têm matas ciliares sombreando águas que parecem limpas e que surgem através dos altos muros e gradis de condomínios fechados. (BOUCINHAS, 2005, p. 50).

Os moradores da região também se interessaram, debatendo o tema e expressando diferentes opiniões. No decorrer do processo, realizaram-se reuniões, oficinas, visitas, e foi criada a Fundação Aldeia de Carapicuíba, com a participação diversificada de residentes da Aldeia e seu entorno: comerciantes, donas de casa, arquitetos, pedagogos, biólogos.

Durante o processo de desenvolvimento desse projeto, desde 1994 Boucinhas atendeu às diretrizes e orientações do Instituto do Patrimônio Histórico e Artístico Nacional (Iphan). No entanto, verificou que os profissionais desse órgão se restringiam a fazer apreciações e orientações concernentes ao Quadrilátero com suas edificações tombadas, sem considerar o entorno próximo, mobilidade, nascentes, córregos e questões relativas à preservação ambiental da microbacia do córrego Anhembi, onde se localiza o Quadrilátero da Aldeia. Desvendava-se, assim, um problema recorrente, existente, muitas vezes, nos órgãos estaduais e municipais: a falta de conexão entre as diversas secretarias em decorrência de uma forma de construção do conhecimento que isola disciplinas e não abrange a necessária interdisciplinaridade para perceber o mundo.

Nas adjacências da Aldeia de Carapicuíba, na década de 1960, surgiram condomínios fechados com lotes grandes e loteamentos ocupados por moradores procurando melhores condições de vida: verde, sossego e paz, somente a vinte quilômetros da cidade de São Paulo. Perto da Aldeia, o antigo Sanatório Anhembi, atual Faculdade da Aldeia de Carapicuíba (FALC), permanecia, na época:

[...] abandonado com seus $120.000 \mathrm{~m}^{2}$, [...] lugar de aventuras; pelo buraco do muro temos acesso a um mundo mágico de águas puras, nascentes, vegetação exuberante, 
escadarias, caminhos, monumentos, capela e edifícios em ruínas. $E$, também, de tráfico de drogas. (BOUCINHAS, 2005, p. 50).

No final da década de 1990, a Aldeia atravessava rápido processo de degradação, e vislumbrava-se que seria comprometida por intensos impactos provocados pela construção do rodoanel Metropolitano, cuja implantação estava em discussão em diversas instâncias. Existia a expectativa sobre a ação dos poderes públicos para a restauração das casas da Aldeia e a valorização das suas tradições culturais - danças, cantos, violeiros, festas, ações que fazem parte do patrimônio histórico cultural - e a realização de um parque em seu entorno. Mudanças político-administrativas, muitas vezes, são impedimentos para o prosseguimento desses projetos.

\section{O LUGAR E SUA HISTÓRIA}

Com o intuito de melhor compreensão do tema, será feito, de modo resumido, o histórico desse patrimônio. A Aldeia de Carapicuíba, fundada em 1580, é um dos doze aldeamentos jesuíticos remanescentes do processo de urbanização de São Paulo, criados para proteger a cidade e domesticar os índios guaianases ${ }^{2}$. Segundo Francisco de Assis Carvalho Franco, citado por Lemos, Mori e Alambert (2008), Carapicuíba não foi uma aldeia criada pelos jesuítas, alocada para confinar indígenas convertidos; surgiu como um depósito de índios caçados por Afonso Sardinha. Os autores aludem, também, a Manoel da Fonseca, asseverando que Sardinha realizou uma doação "testamentária" de parte de sua sesmaria para ali serem "aldeados" somente índios libertos, e que aos escravizados, recém-chegados do sertão, dava-se outro destino, atualmente ignorado ${ }^{3}$. Estava presente nesses aldeamentos, a conexão entre duas culturas, o que se manifestava na comunicação oral desde os inícios da colonização, já que em:

[...] São Paulo, uma área de grande densidade populacional indígena, falava-se a língua geral, ou tupi. Com o Diretório (1758), a língua portuguesa foi implantada em São Paulo [...] A língua geral era falada nos arredores da Vila, área em que se concentravam os aldeamentos indígenas. (OLIVEIRA, 2005, p. 1).

A Aldeia de Carapicuíba é um marco arquitetônico e histórico da Região Metropolitana de São Paulo (RMSP). Permanecem, em 2016, edificações remanescentes do século XVIII, que a marcam. É patrimônio histórico ${ }^{4}$ declarado pela Secretaria do

2 Segundo Barcellos, $(2007$, s/p.), "[...] guaianazes são guaranis".

3 As varias opiniões a respeito da função dessa Aldeia demonstram que não há acordos, mas discutir essa questão foge ao escopo deste artigo.

4 Segundo Faccio (2010, p. 62), faz parte do Livro Tombo Arqueológico, Ełnográfico e Paisagístico da Secretaria do Patrimônio Histórico e Artístico Nacional, folhas 3, com número de inscrição sete, que o Conjunto Arquitetônico e Urbanismo da Aldeia de Carapicuíba, situada no Município de Cotia, Estado de São Paulo, propriedade da Prefeitura Municipal e outros, processo número 218/39, o registro do tombamento ex-officio de 13 de maio de 1940. 
Patrimônio Histórico e Artístico Nacional (SPHAN), conceituado como exemplo especial de aldeamento paulista jesuítico. Seu valor permanece, sobretudo, na disposição espacial original, definida por construções que sustentam sua volumetria em relação com o patrimônio jesuítico. Ainda hoje (2016), é um marco nacional de importância, que representa a memória do processo da colonização europeia no Brasil (ZAHN; FEITOSA; SAWAYA, 2008). Apenas a capela de São João Batista ${ }^{5}$ foi tombada pelo Condephaat, porém trata-se de um tombamento ex-officio, já que todo o conjunto foi tombado em 1940 pelo Iphan, considerando os critérios que determinam um Núcleo Histórico ao restituir-lhe os traços de 1736. (FACCIO, 2010, p. 64). O valor desses núcleos existe no conjunto e não nos edifícios isolados, considerando-se que precisa ser conservada a importância do todo. Na ocasião do tombamento da Aldeia pelo Iphan, foram desenhadas uma planta e uma perspectiva aérea realizada por Luis Saia ${ }^{6}$ (figuras 1 e 2):

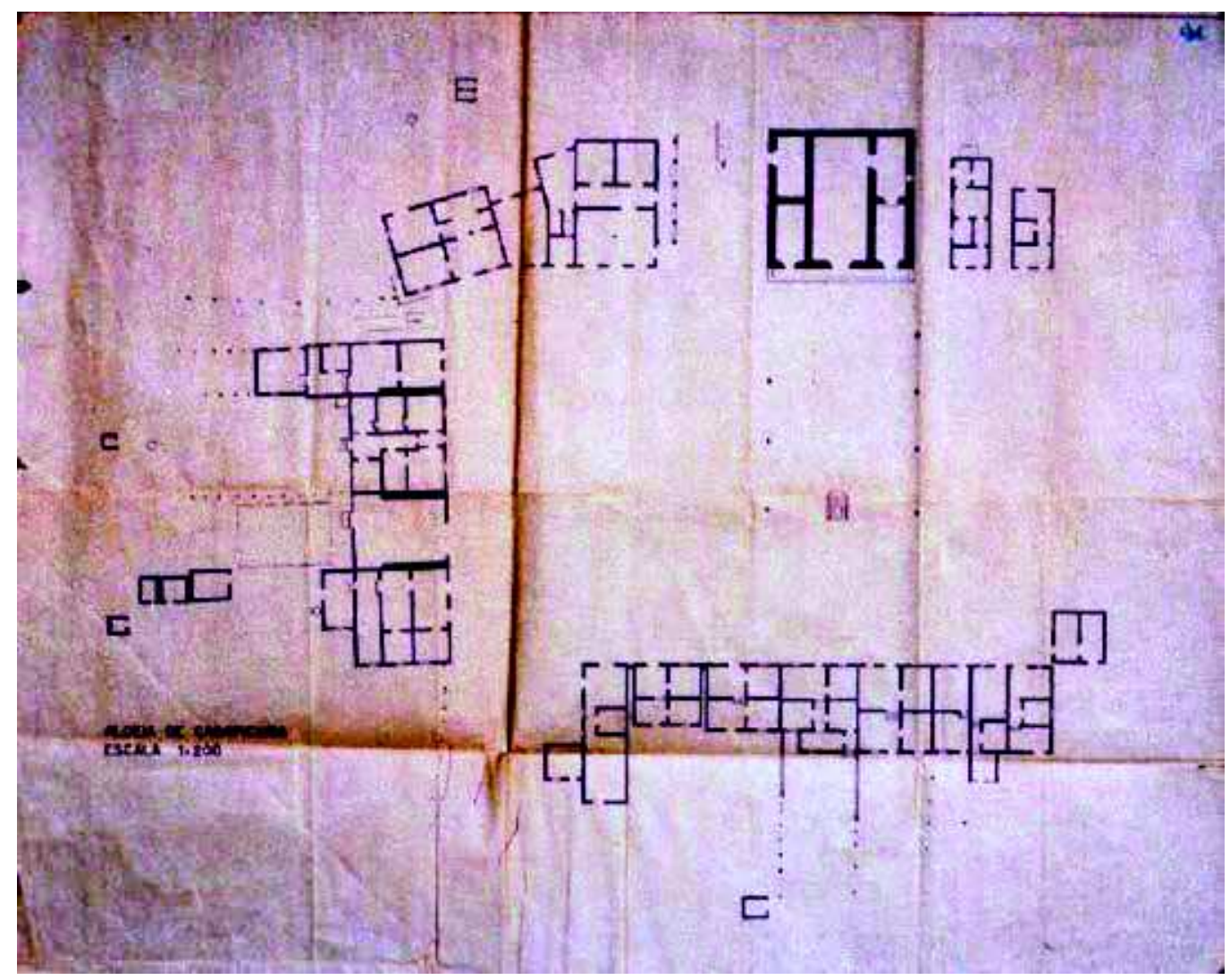

Figura 1 Planta da Aldeia de Carapicuíba. (FACCIO, 2019, p. 60).

Fonte: Secretaria Regional do Iphan do Rio de Janeiro.

Segundo Faccio (2010, p. 64), consta no Processo Condephaat n 339/1973, fls. 9.

6 Luis Saia é um renomado arquiteto, engenheiro, colaborador do Departamento de Cultura e do então Serviço do Patrimônio Histórico e Artístico Nacional, onde substituiu Mario de Andrade na Chefia do $4^{\circ}$ Distrito, cargo que exerceu por quarenta anos. 


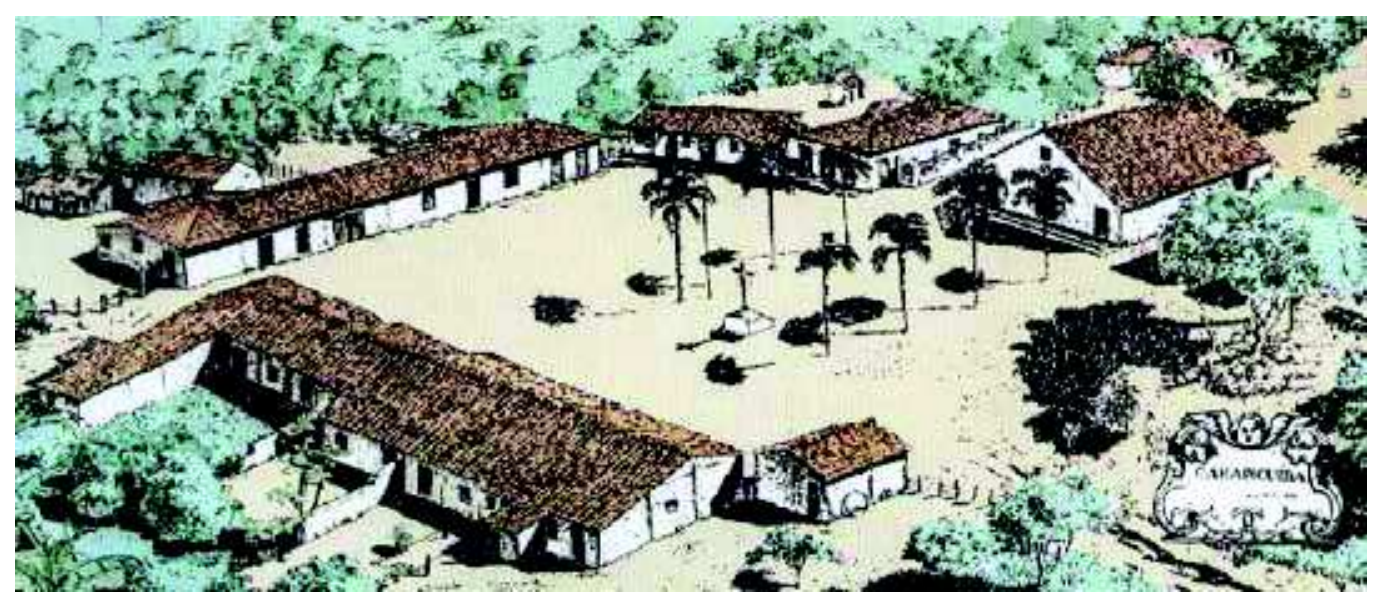

Figura 2 Perspectiva da Aldeia de Carapicuíba realizada por Luís Saia (1938), que fez o primeiro estudo sobre a Aldeia durante a gestão de Mario de Andrade.

Fonte: Andrade (2006, p. 24, apud FACCIO, 2019, p. 60).

Em 1698, os jesuítas destruíram a Aldeia de Carapicuíba, porém foi reconstruída no mesmo lugar, em 1736, com base em três paredes de taipa que restavam do século $X V I$, e que sobreviveram, da antiga capela de São João Batista - que, a partir de então, chamou-se capela de Nossa Senhora da Graça. (FACCIO, 2010, p. 67). A destruição pelos jesuítas teve a justificativa de que as terras de plantio estavam cansadas, para que os índios as abandonassem e mudassem para a Aldeia de Itapecerica ${ }^{7}$. Condicionada a esses remanescentes, a Aldeia de Carapicuíba evoluiu para uma arquitetura caipira e desenvolveu-se em volta de uma praça retangular demarcada por casas de taipa de mão (LEMOS; MORI; ALAMBERT, 2008, p. 93). Como diz Boucinhas, as construções ainda são de:

[...] taipa de sopapo, com exceção da igreja e algumas paredes das casas, que são de taipa de pilão; o pátio, retangular, de chão batido e inclinado como o terreno natural [...]. Em frente à igreja, um plano horizontal com arrimos de pedra, dez palmeiras jerivá [...] alinhadas em duas filas, da igreja até o cruzeiro; ao redor do pátio, as casas onde funcionam o posto policial, dois bares, mercearia, frutaria, farmácia, correio, a casa de cultura da Prefeitura, residências e vestíbulo de um restaurante. No entorno, mais residências, alguns sítios de fim de semana, três indústrias; à jusante do pátio passa o córrego Anhembi, poluído; à montante, atrás de muros altos, a área do antigo Sanatório Anhembi, com muita vegetação e águas límpidas. Todas as paredes das casas da Aldeia são caiadas de branco com barra azul-clara e portas e janelas com seus batentes azul-escuros; no pátio, postes, fio elétrico, ônibus, caminhões, carros, bicicletas [...] (BOUCINHAS, 2005, p. 48-49).

Consta que a atual avenida Inocêncio Seráfico é remanescente do caminho trilhado pelos guaianases que habitavam Carapicuíba anteriormente à chegada dos colonizadores portugueses. Esses índios, afastando-se do caminho de Cotia, desciam até o rio

O que consta, segundo Faccio, (2010, p. 65) no Processo Condephaat n 339/1973, fls. 4. 
Tietê para pescar e banhar-se. Em suas andanças, aí se estabeleceram, construindo uma taba, suas ocas, gérmen da atual Aldeia.

Ainda que tombada pelos órgãos de preservação, que definem que qualquer obra, modificação ou reforma no local e no entorno, num raio de 300 metros, só pode ser realizada com a aprovação desses órgãos, em 1997, com limitações, não tinham condições de fiscalizar e manter os espaços e as edificações sob controle. (BOUCINHAS, 2005, p. 49).

\section{O PROJETO PARTICIPATIVO COM BASE NO ESTUDO DO MEIO INTERDISCIPLINAR}

No decorrer de 1997, realizou-se uma experiência com caráter interdisciplinar, da qual a maioria dos autores deste artigo participou, de maneira conjunta entre um grupo formado majoritariamente por arquitetos, alunos da pós-graduação da Faculdade de Arquitetura e Urbanismo da Universidade de São Paulo (FAUUSP) e um grupo de professores, funcionários e alunos da Escola Estadual de Primeiro Grau (EEPG) Professora Esmeralda Becker Freire de Carvalho, ${ }^{8}$ na Aldeia de Carapicuíba e seu entorno. Essa ação entrelaçou diferentes níveis de ensino na recuperação e construção de sentimentos de valorização e pertencimento a um lugar considerado patrimônio histórico e ambiental, relacionando-se com a noção de participação da comunidade, o que possibilitou e facilitou a preservação de um patrimônio histórico e ambiental, abrindo um espaço importante na articulação de níveis de ensino.

A experiência confirmou a importância da relação arte-percepção, que transcende o mero observar ao transformar-se em um instrumento contra a alienação, da qual faz parte o sentimento de não pertencimento aos lugares de vida, nesse caso, um patrimônio histórico ambiental. Ao incentivar a escola a ocupar os espaços da arte como desenvolvimento da percepção, também se abriu a possibilidade de maior valorização do patrimônio histórico ambiental e cultural. Uma das ações efetivadas com esse processo foi a execução, ainda que parcialmente em relação ao projeto original, do hoje chamado Parque Ecológico Aldeia de Carapicuíba, que só foi possível pelo envolvimento direto da comunidade.

Na primeira visita a campo, realizada na disciplina de pós-graduação, a Aldeia foi apresentada, primeiramente, como perdida no tempo, sonolenta e em silêncio: que segredos estariam escondidos naquele lugar histórico de São Paulo? Após andar pelas encostas adjacentes à Aldeia à procura de informações, o grupo de estudantes de

\footnotetext{
O trabalho fazia parte da disciplina de pós-graduação Projeto sensível, projeto tecnológico, suas relações, ministrada pelo professor Sylvio Sawaya, com a consultoria do arquiteto Caio Boucinhas, uma equipe de arquitetos (alunos de pós-graduação), formada por Denise Falcão Pessoa, Ely Ana de Oliveira Araujo, Paulo Chiesa, Regina Cardarelli e Sylvia Adriana Dobry-Pronsato. Estes (exceto Paulo Chiesa) também participaram da pesquisa sobre a Aldeia de Carapicuíba, realizada no Centro Universitário Nove de Julho (Uninove), coordenada pela profa. dra. Maria José Feitosa, com consultoria do prof. dr. Sylvio Sawaya (FAUUSP) e a participação do prof. dr. Carlos Eduardo Zahn (Uninove/FAUUSP), dos profs. Eliana Quartim Barbosa, Luiz Otavio de Faria e Silva, Sergio Torres Moraes e dos arquitetos Maria de Lourdes Nogueira, Roberto Mello e Roberto Dantas Araujo. Essa experiência realizou-se sob a coordenação pedagógica da profa. dra. Nidia Nacib Pontuschka, da Faculdade de Educação da USP (FEUSP), sendo diretora da escola, na época, Maria Helena Scabelo.
} 
pós-graduação deparou-se com a Biblioteca e a Casa de Cultura, cujos funcionários sugeriram conhecer a escola. A diretora narrou histórias do dia a dia, da vergonha que muitos sentem por serem descendentes de índios, dos migrantes, das ruas de barro, das crianças, da vontade de crescer, dos jerivás (palmeiras nativas muito presentes em São Paulo). Foi a partir desse contato que se originou a ideia de um Estudo do Meio, inicialmente acadêmico, que se estendeu para fora dessa fronteira, compreendendo um estudo para a implantação de um projeto participativo de revitalização urbana e paisagística da área, denominado "Parque Ambiental Aldeia de Carapicuíba". Durante o processo de elaboração desse projeto, buscou-se entender o significado de uma interferência urbano-paisagística, respeitando as contradições encontradas, em especial, as problemáticas com relação à população do lugar 9 . Esteve sempre presente a fragilidade e delicadeza evocadas pela Aldeia e a premissa de resgatar seu valor como patrimônio histórico, por ser testemunha dos primeiros contatos que a colonização portuguesa teve com a população indígena que residia na região. Entre os objetivos a serem atingidos nesse trabalho interdisciplinar, os mais relevantes foram:

- desenvolver um estudo do meio interdisciplinar, tendo como eixo principal a arte; recuperar e preservar a história, a cultura e os recursos naturais da Aldeia de Carapicuíba;

- conhecer o lugar, o que poderia revelar seus moradores, seus sonhos, suas ações no cotidiano;

- saber como a população de uma Aldeia remanescente da colonização jesuítica, de origem indígena, apropriava-se de seus lugares;

- desenvolver um processo participativo com alunos, professores e moradores da aldeia.

O partido proposto para o parque em 1997, como parte do trabalho desenvolvido durante a disciplina de pós-graduação "Projeto sensível, projeto tecnológico, suas relações", ministrada pelo professor Sylvio Sawaya, com a consultoria do arquiteto Caio Boucinhas, contemplou que a bacia do Ribeirão Carapicuíba e seus afluentes, que compõem a bacia de Carapicuíba, se inclui no Quadrilátero da Aldeia de Carapicuíba. As figuras 3 e 4 ilustram essa ideia.

As questões desse lugar e seu significado como patrimônio histórico foram surgindo e definiram-se, entre outras, as marcas e lendas da cultura tupi:

Há um elo muito forte dos moradores e da vizinhança com a Aldeia; suas relações vão surgindo, há mistérios, estórias sobrenaturais, milagres e há também conflitos quanto ao destino da Aldeia: uns desejam que permaneça intocável, outros que seja um centro turístico nacional, [...]; e outros, ainda, não se incomodariam se ela fosse demolida e a malha urbana vizinha passasse por cima de tudo. Há também os que a veem como área de valor histórico importante que precisa ser recuperada com sensibilidade e respeito: nela não cabe sofisticação, nem lampiões, nem vegetação

9 Esta experiência de projeto participativo foi descrita com maior detalhamento em Dobry-Pronsato (2005). 
é um testemunho de um espaço jesuítico surgido neste lugar, naquele tempo, com funções claras e hoje precisa que se criem condições para novos usos que a mantenham viva. [...]. (BOUCINHAS, 2005, p. 50)

\section{PARQUE AMBIENTAL D O CARAPICUIBA}

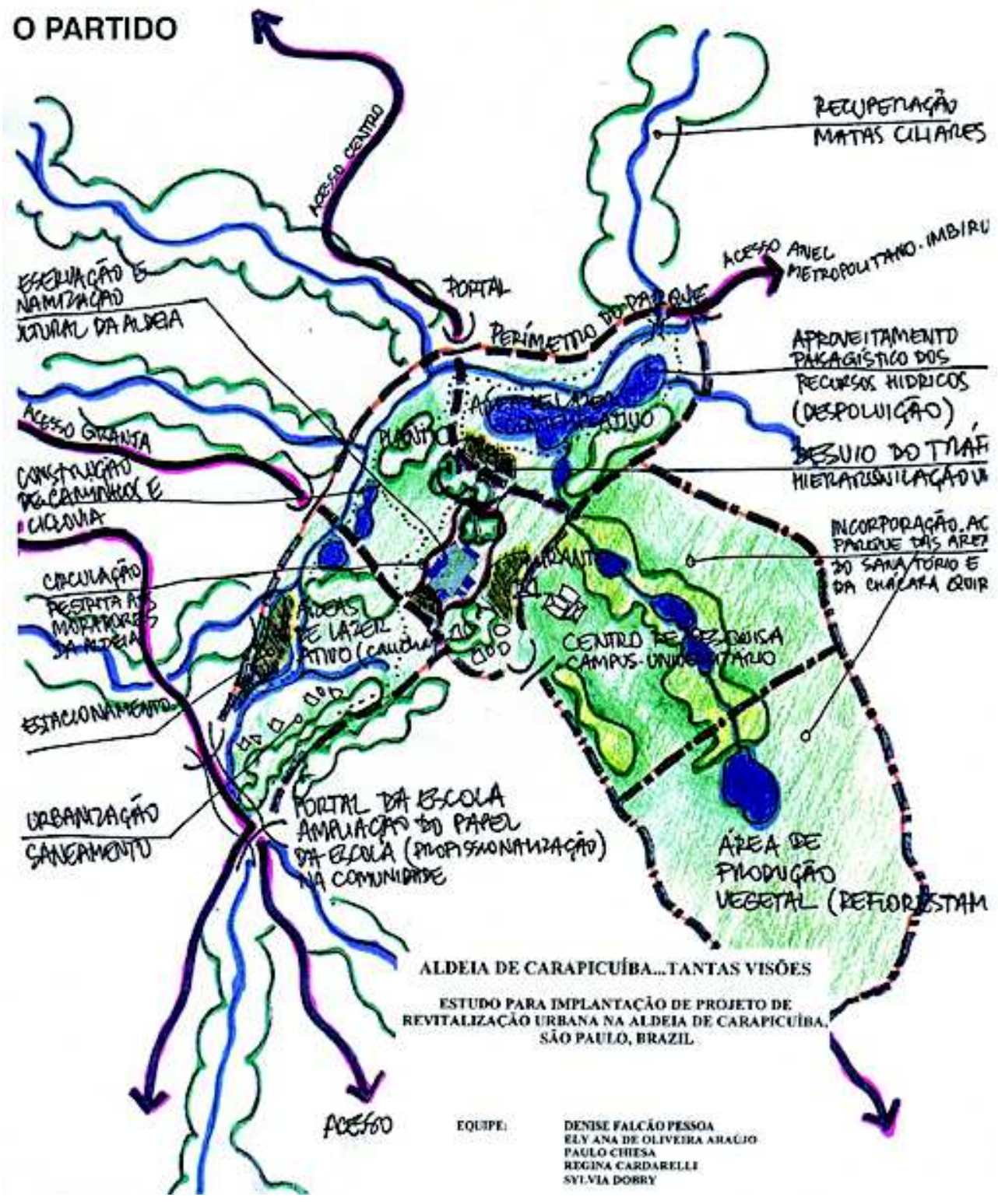

Figura 3 Partido proposto em 1997, na época com o nome de Parque Ambiental Aldeia de Carapicuíba. Fonte: Dobry-Pronsato (2005, p. 44). 


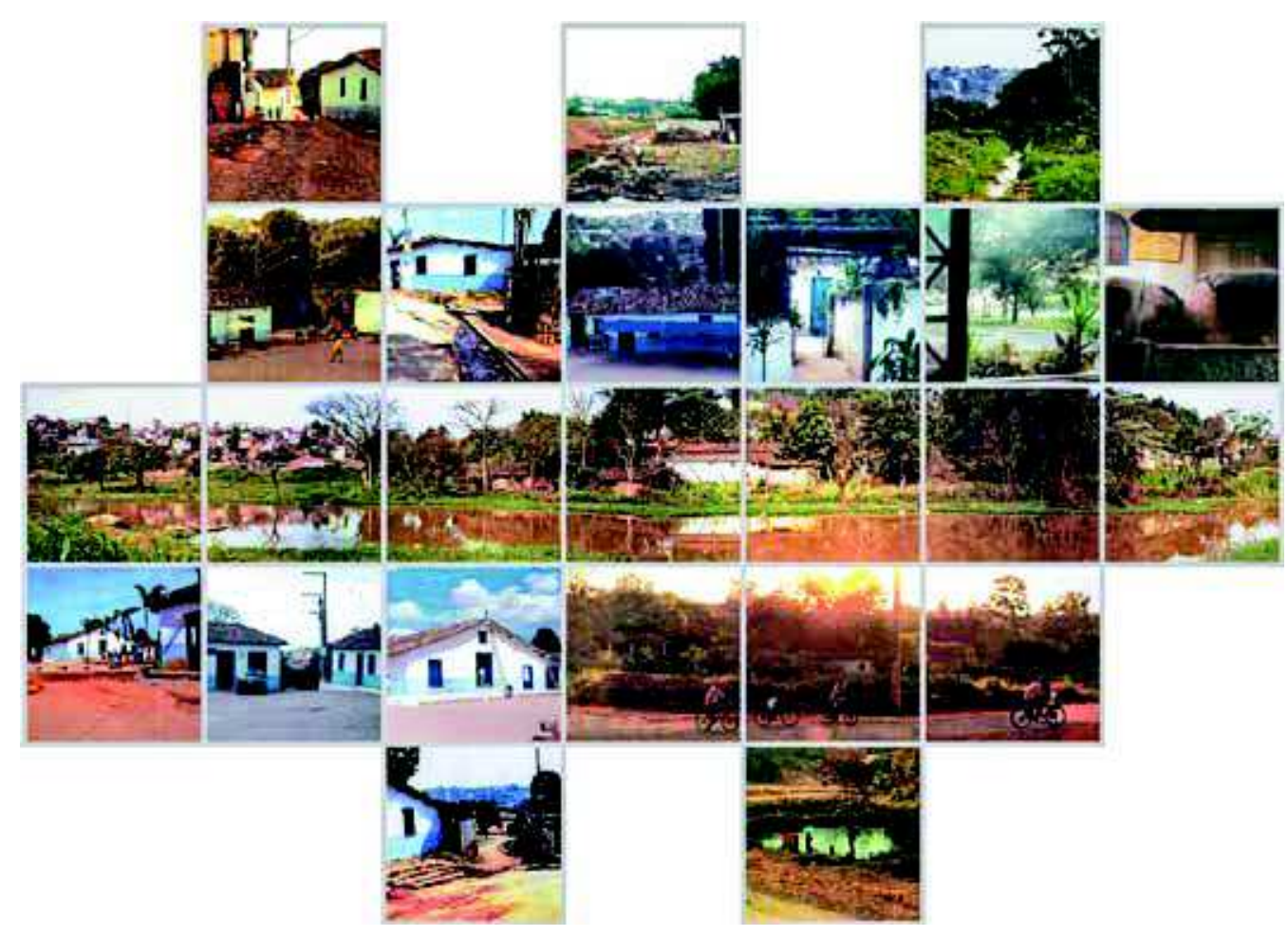

Figura 4 Aldeia de Carapicuíba e entorno, fotos realizadas durante o Estudo do Meio.

Fotos: Denise Pessoa, Ely Ana Araúio e Regina Cardarelli, 1997.

Fonte: Dobry-Pronsato (2005, p. 41).

O Estudo do Meio ${ }^{10}$ foi uma experiência realizada na Aldeia de Carapicuíba por alunos da pós-graduação da FAUUSP, professores, funcionários e alunos da EEPG Professora Esmeralda Becker Freire de Carvalho, com a participação do arquiteto Caio Boucinhas' ${ }^{11}$. Nesse estudo, o processo da arte teve papel fundamental para o desenvolvimento da percepção ambiental, integrando o projeto de intervenção paisagística com a educação ambiental e a conscientização da importância de morar em um lugar considerado patrimônio histórico e ambiental.

É necessário esclarecer que está se conceituando aqui o sentido ampliado da arte cunhado por Joseph Beuys, para o qual todo ser humano é considerado artista, sem querer dizer que todos fossem artistas profissionais. A ideia de arte ampliada, na visão de Beuys, resgata a condição de criatividade inerente aos homens e a importância de desenvolvê-la:

10 A profa. dra. Nidia Nacib Pontushka, na primeira reunião, discorreu brevemente sobre o Estudo do Meio, que priorizava a observação direta da realidade, substituindo o aprendizado entre as paredes da sala de aula. Adotando esse método, a escola não pode ser entendida de modo isolado: organiza uma forma de ensino que inclui a participação de muitos: alunos, diretores, professores, funcionários, moradores, pais. O Estudo do Meio, como método interativo, pode criar expectativas que nos obrigam a pensar sobre o retorno do projeto à comunidade. Ao longo de um ano realizaram-se reuniões mensais entre os arquitetos participantes e professores e funcionários da escola. Os professores da escola, por sua vez, praticavam estudos do meio com seus alunos, transpondo os conhecimentos interdisciplinares nascidos nas reuniões à sala de aula.

11 Como dito anteriormente, o arquiteto Caio Boucinhas cumpria função de assessor na disciplina de Pós-Graduação e também era contratado pela prefeitura para desenvolver o projeto. 
Parque Ecológico Aldeia de Carapicuíba: Projeto de Paisagismo Participativo Valorizando um Patrimônio Histórico

Beuys enfatiza a relação antropológica da arte, não a considerando apenas como peça de museu. Para ele a criatividade é a ciência da liberdade. Enfatiza que todo saber humano provém da arte e que a ciência se desenvolveu a partir do criativo... Assim a história pode ser vista de forma plástica. Assim a história é vista como escultura. (DOBRY-PRONSATO, 2005, p. 132).

Da mesma maneira, pode-se entender a paisagem como arte, sendo ação dos homens. Ao questionar a obra de arte singular, Beuys entende que, [...] o que mais interessa é a educação artística do ser humano. (DOBRY-PRONSATO, 2005, p. 132).

Foi possível resgatar, por meio de relatos de avós e pais de alunos, memórias de lendas indígenas mantidas por transmissão oral e a vivência da dança de Santa Cruz, que inspiraram o desenvolvimento de poesias, desenhos, maquetes, que foram apresentados em exposições em diversos lugares da Aldeia. No contexto da experiência descrita, Valdomiro Rolim da Costa, um dos professores de português, realizou um belo trabalho de poesia com alunos da $6^{a}$ série. Um deles escreveu:

Aldeia que se originou das cinzas dos índios.

Quase ninguém liga, que desespero!

Uma paisagem onde não se vê quase nada.

Uma aldeia perdida no ar da ignorância humana

Como já dito anteriormente, o processo de desenvolvimento da arte teve papel central no desenvolvimento da percepção histórico-ambiental. Isso pode ser avaliado considerando-se que muitos dos professores da escola que participaram dessa experiência interdisciplinar declararam que nela trabalhavam há muitos anos (entre sete e dezessete) e não sabiam da história da Aldeia de Carapicuíba e nem da importância da sua preservação. Disseram que todos os dias iam em seus carros ou em ônibus, davam suas aulas e voltavam às suas casas sem olhar para esse lugar em volta da escola.

Essas atividades foram modos de restituição da Aldeia à comunidade, da efetivação de outras ações de divulgação, como conferências a estudantes das unidades de ensino abrangidas e universitários de arquitetura visitantes, oriundos da Holanda, e da participação de pessoas que integravam o Movimento Ambientalista pelo Patrimônio da Aldeia de Carapicuíba (Mapac). Assim, o processo de restituição da memória desvenda o sentido de enraizar no passado o presente de uma comunidade que, ao mesmo tempo, se reconstrói nas festas tradicionais da Aldeia de Carapicuíba, miscigenando subsídios das culturas religiosas católica, negra e indígena (figuras 5 e 6):

Aí, todos os anos, em maio e outubro, se realizam as festas tradicionais da Aldeia e aí, também, saem e chegam as romarias a cavalo para Santana do Parnaíba e Aparecida. As festas são feitas de cantorias, danças e comilança - a feijoada do sábado e a canja para os violeiros e seus acompanhantes na última madrugada. (BOUCINHAS, 2005, p. 49). 
Sylvia Adriana Dobry-Pronsato, Caio Boucinhas,

Antônio Busnardo Filho e Denise Falcão Pessoa

Cooperando com a conservação da tradição das festas, a Associação dos Moradores da Aldeia de Carapicuíba, fundada em 1996:

[...] se anima nas proximidades das festas; as músicas, as cantorias, as danças são aprendidas nos ensaios para as festas, enquanto são montados o pau-de-sebo e o mastro de São João. No começo da noite o movimento de caminhões, carros, ônibus vai rareando, a iluminação elétrica é deficiente; o pátio vai entrando num clima mágico, de mistério e calma. Parece um lugar muito longe da agitação metropolitana. (BOUCINHAS, 2005, p. 50).

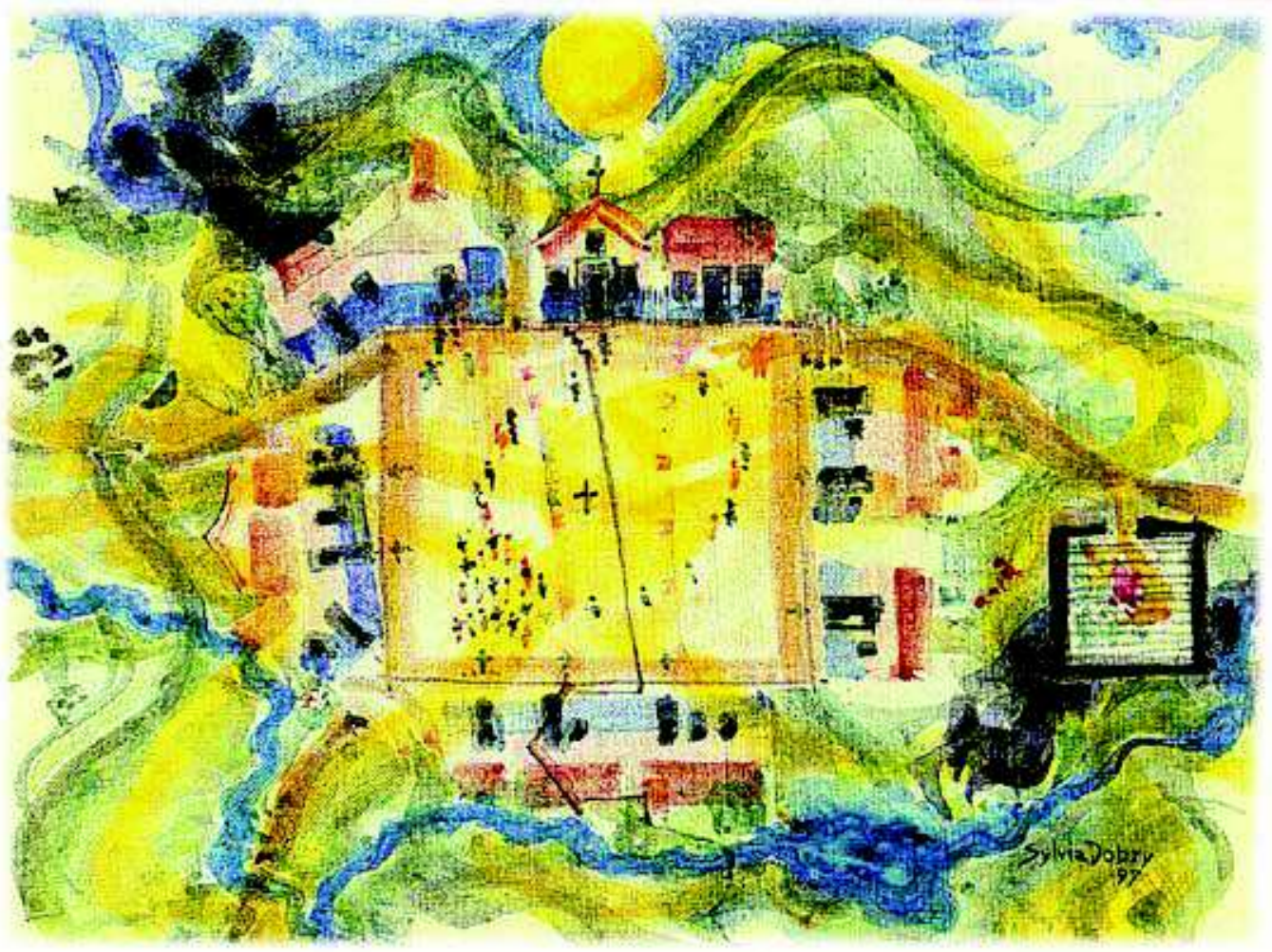

Figura 5 A festa na Aldeia de Carapicuíba. Aquarela sobre tela, de Sylvia A. Dobry, 1997. Tamanho original, $0,40 \mathrm{~m} \times 0,30 \mathrm{~m}$.

Fonte: Dobry-Pronsato (2005, p. 135).

Com a urbanização, a palavra cultura abraçou também o sentido de qualidade de vida mais humana, assumindo que: "[...] cultura é o conjunto das práticas, das técnicas, dos símbolos e dos valores que se devem transmitir às novas gerações para garantir a reprodução de um estado de coexistência social." (BOSI, 1992, p. 16). Esse conceito convive com outra ideia de cultura, entendida como consciência de um presente com fortes desequilíbrios, que norteia desígnios para um futuro meIhor - porém a urbanização compreende também deslocamento das pessoas, o que, na Aldeia, colaborou para o desaparecimento da memória. Revigorar essa memória é, então, tarefa cultural relevante para cunhar o elo entre passado, presente e futuro, essencial para a valorização do patrimônio histórico e paisagístico. 


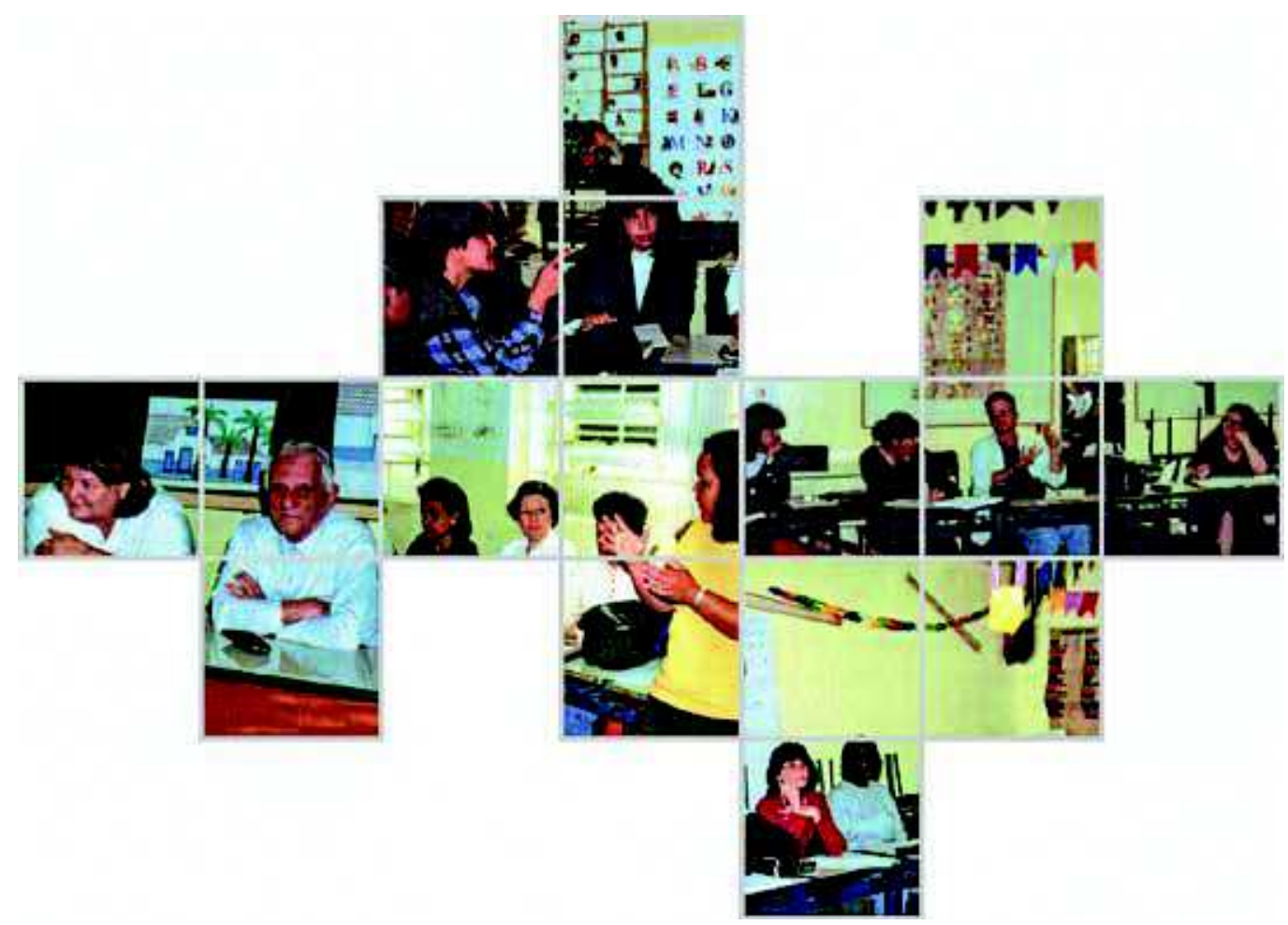

Figura 6 Reunião do Estudo do Meio na EEPG Professora Esmeralda Becker, com o historiador convidado, Miguel Costa Jr., morador da região. Fonte: Dobry-Pronsato (2005, p. 42).

Fotos: Denise Pessoa, Ely Ana Araújo e Regina Cardarelli, 1997.

Na leitura contextualizada dos espaços urbano-paisagísticos estudados, considerando-se a convergência entre o poder administrativo e a afetividade dos moradores, é possível compreender a complexidade, a variabilidade e a diversidade de ações abertas à participação da sociedade, permitindo aflorar o imaginário dos moradores como base de fortalecimento do sentido de pertencimento ao lugar. Isso possibilitou perceber a cidade como espaço de todos e direito de todos os seus cidadãos. Como tal, demonstrou o dever de todos para a concepção e preservação dos espaços públicos enquanto lugares de convivência e de construção do conhecimento - entendido não somente como apropriação intelectual, mas como relação entre objeto conhecido e sujeito cognoscente, como uma gnoseologia do lugar, que, em sentido amplo, permite o estudo de todas as formas de conhecimento, inclusive o estudo do espaço urbano. Nesse sentido, espaço urbano, imaginário social e conhecimento constroem e revelam o genius loci, que dá autenticidade ao lugar.

\section{O PROJETO DO PARQUE ECOLÓGICO ALDEIA DE CARAPICUÍBA}

O projeto do parque procurou harmonizar os recursos naturais e a ocupação humana desde a Aldeia Jesuítica de 1580 até as residências nas áreas das nascentes. As premissas que orientaram o projeto foram: 
- destacar a importância de um parque no entorno da Aldeia de Carapicuíba como cinturão protetor do patrimônio histórico e sua valorização, uma vez que preserva a eleição original do sitio;

- recuperar as edificações tombadas da Aldeia;

- conectar o parque público com a área rica em recursos naturais - flora, fauna, recursos hídricos - da grande chácara murada, onde estava sendo implantado, com apoio da prefeitura, um centro universitário;

- acolher atividades de turismo gastronômico, histórico, cultural (ateliers de arte, educação artística, capoeira, maracatu, esporte);

- valorizar e incentivar a percepção do pedestre, projetando caminhos que conectem o ambiente histórico cultural e o ambiente natural.

Contemplou-se a necessidade de estacionamento para carros sem impactar a estabilidade da Aldeia e de resolver as questões de drenagem de águas pluviais que esburacavam o pátio.

Nos levantamentos e diagnósticos, vistorias e passeios com moradores, surgiram histórias de um antigo lago, nascentes de onde tiravam água para beber. Combinou-se, com moradores e técnicos, que as casas próximas às nascentes deveriam ser retiradas, e o projeto contemplou a realização de dois lagos. Foi executado, até 2016, apenas o da nascente, e não o que aproveitava a água do córrego e acolhia um deque, palco de um teatrinho/cinema ao ar livre. $\bigcirc$ projeto desse lago levou em consideração a topografia: a arquibancada/plateia do palco/deque sobre o lago desenvolvia-se no suave talude existente (figura 7).

Em relação ao projeto de plantio, predominaram árvores nativas, levando em consideração árvores existentes, de origem portuguesa, que foram reconhecidas na etapa de diagnóstico, como os pés de castanha portuguesa (Castanea sativa), testemunhas do período de colonização.

Do projeto proposto, foram executados: o piso do pátio central da Aldeia, com a drenagem de águas pluviais, o trecho sul do parque, a casa das atividades educativas e culturais - anexada a uma edificação tombada -, algumas trilhas, parte da vegetação prevista (figura 8).

Hoje (2016) ainda que seu projeto original tenha sido executado parcialmente, o parque, considerado imenso por seus frequentadores, possui capacidade para 80 mil pessoas, sendo o principal local de diversão e recreação da população. Contém ciclovias, playground, praça de eventos e pistas para caminhadas, que passam dentro de bosques ao redor do lago, mesas, bancos, churrasqueiras em lugares agradáveis para acomodar da melhor maneira os frequentadores. $\bigcirc$ espaço é aberto para o comércio de vendedores ambulantes e para os artesãos da região exporem seus trabalhos. Também são armadas barracas de lanches, frutas, caldo de cana e outros alimentos. 


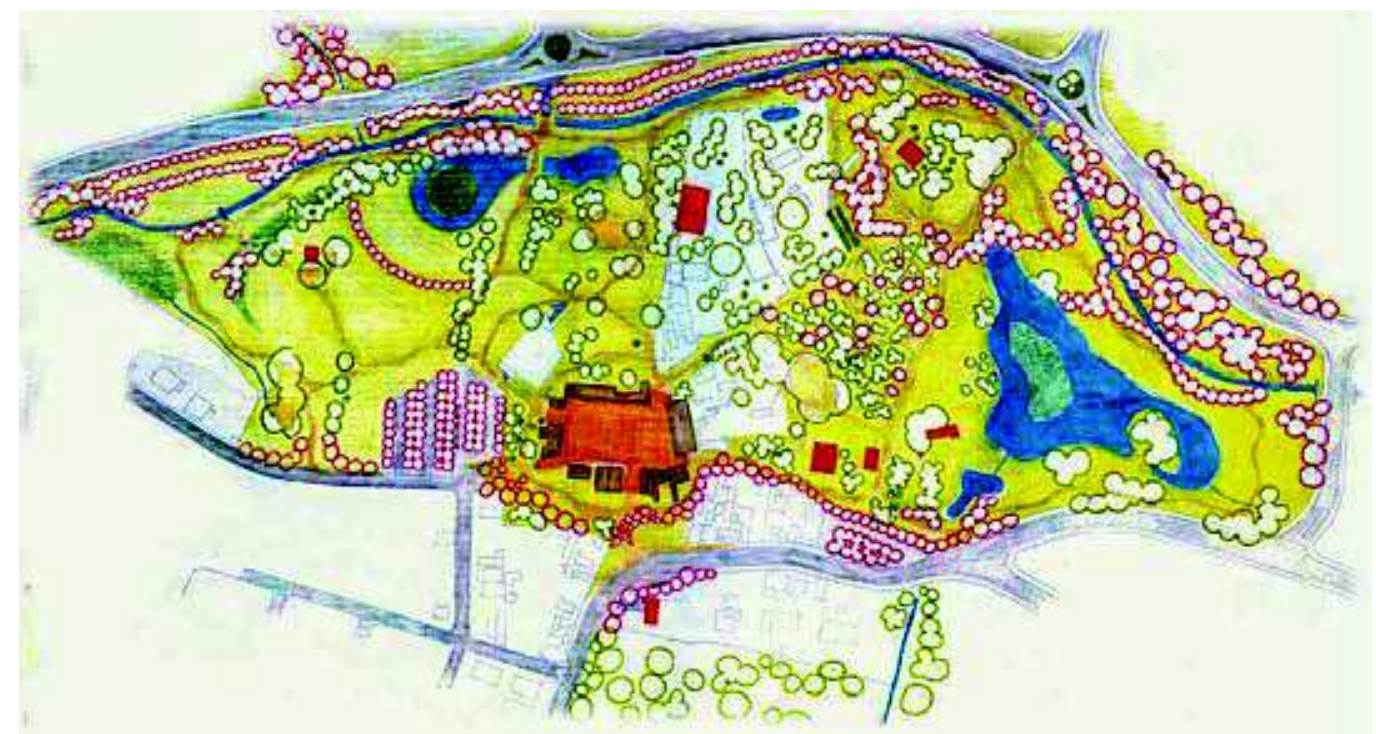

Figura 7 Anteprojeto para o Parque Ecológico Aldeia de Carapicuíba. Desenho de Caio Boucinhas, 1994. Fonte: Dobry-Pronsato (2005, p. 20).

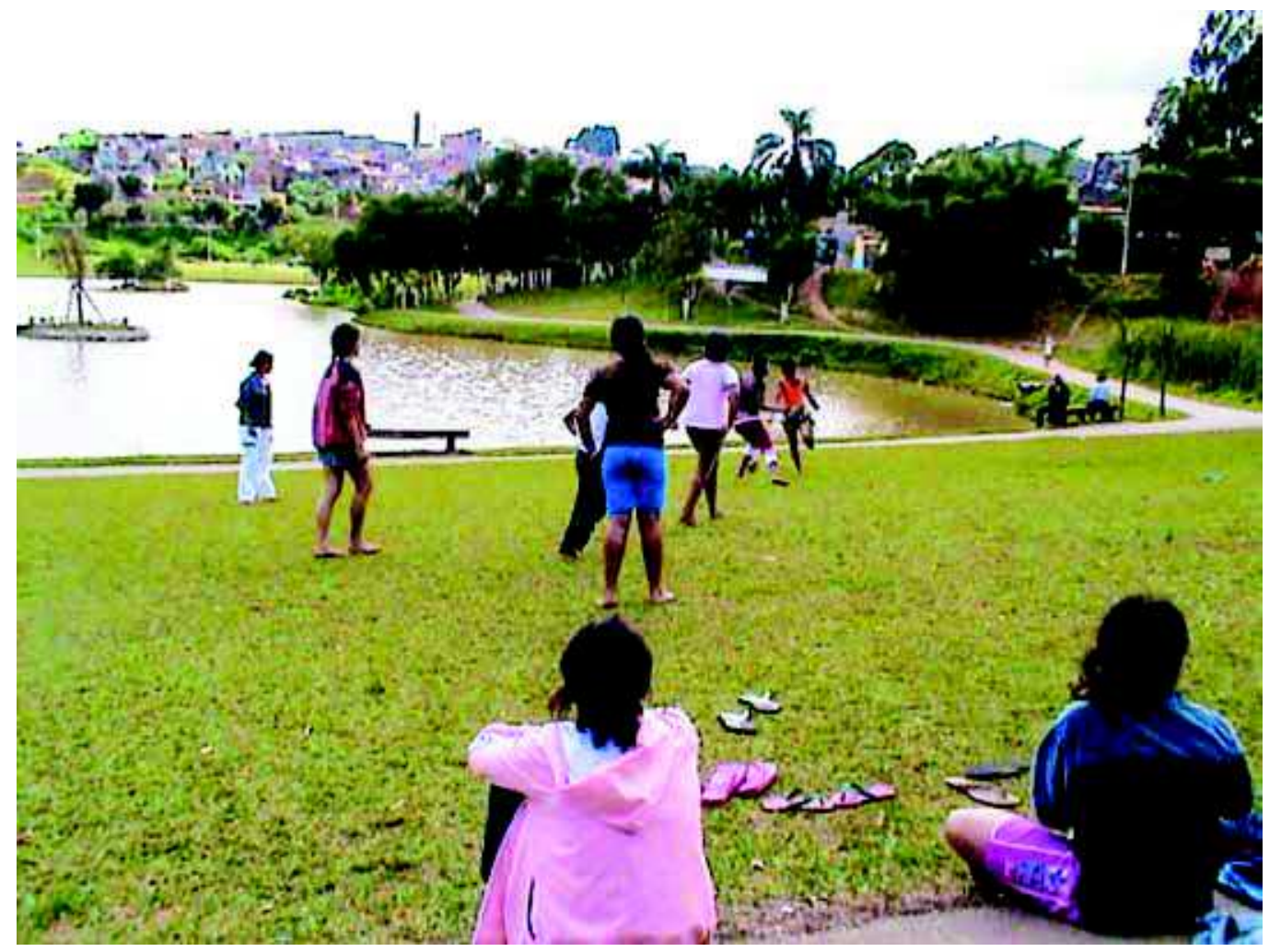

Figura 8 Trecho do parque implantado.

Foto: Caio Boucinhas, fev. 2005. 
Sylvia Adriana Dobry-Pronsato, Caio Boucinhas,

Antônio Busnardo Filho e Denise Falcão Pessoa

\section{CONSIDERAÇÕES FINAIS}

A metodologia de projeto participativo evidenciou a possibilidade de articulação entre a ação pedagógica e a do arquiteto urbanista quando ambas entretecem um modo interativo, dinâmico e dialógico. Confirmou-se que as escolas podem permitir uma vinculação mais intensa entre os moradores e seus lugares de vida e, no caso da Aldeia de Carapicuíba, toma maior importância ao se tratar de um lugar que é patrimônio histórico e ambiental. Isso ocorre porque as escolas são lugares ricos em energias, encontros, disposições a pensar e ver novas formas de perceber. Porém, as escolas também são campos de conflitos e desvendam as contradições da sociedade. Não obstante as falhas pedagógicas e físicas, devido muitas vezes ao desamparo a que é relegado o ensino público no Brasil, as escolas têm probabilidades de se converterem em ambientes de intercâmbio de conhecimentos, de focos que irradiam ações coletivas e de mudanças, tais como a construção de sentimentos de pertencimento ao lugar e valorização da identidade.

O processo vivenciado na Aldeia de Carapicuíba permitiu a participação da comunidade, o que possibilitou e facilitou a preservação de um patrimônio histórico e ambiental, revelando o lugar, muitas vezes oculto, a cada um dos participantes. Significou descortinar o lugar cotidiano, descobrir sentidos mais profundos e valores culturais, o que possibilitou contribuir para a sua inserção na comunidade, e por sua vez, ampliar horizontes de esperança na preservação histórica e ambiental e criação desses lugares, confirmados pela implantação do projeto do parque - hoje com o nome de Parque Ecológico da Aldeia de Carapicuíba -, ainda que parcialmente em relação ao projeto original, pela Prefeitura, o que só foi possível pelo envolvimento direto da comunidade.

\section{REFERÊNCIAS BIBLIOGRÁFICAS}

BARCELLOS, João. Os jesuítas na terra dos Brazis. A Página da Educação, n 173, ano 16, dezembro, 2007. Disponível em: <http://www.apagina.pt/?aba=7\&cat=173\&doc=13084\&mid=2>. Acesso em: 24 jun. 2013.

BOSI, Alfredo. Dialética da colonização. São Paulo: Companhia das Letras, 1992. 422 p.

BOUCINHAS, Caio. Projeto participativo na produção do espaço público. 2005. 230 f. Tese (Doutorado em Estruturas Ambientais Urbanas) - Faculdade de Arquitetura e Urbanismo, Universidade de São Paulo, São Paulo, 2005.

DOBRY-PRONSATO, Sylvia Adriana. Arquitetura e paisagem: projeto participativo e criação coletiva. São Paulo: Annablume/ Fapesp/Fupam, 2005. 148 p.

; BOUCINHAS, Caio; PESSOA, Denise Falcão. Patrimônio histórico e paisagismo participativo: Aldeia de Carapicuíba e seu entorno - tantos olhares. In: CONGRESSO INTERNACIONAL DE REABILITAÇÃO DO PATRIMÔNIO ARQUITETÔNICO E EDIFICADO, 12, 2014, Bauru, Anais... ISSN/ISBN: 978-85-99679, p. 374-382.

FACCIO, Neide Barrocá. A Aldeia Carapicuíba e sua resolução de tombamento. Topos, vol. 4, n 2, 2010, p. 60-108. Disponível em: <http://revista.fct.unesp.br/index.php/topos/article/viewFile/2255/2064>. Acesso em: 26 jun. 2014.

LEMOS, Carlos Alberto Cerqueira; MORI, Victor Hugo; ALAMBERT, Clara Correia d'. Antiga Aldeia de Carapicuíba. In: SOUZA, Marisa Campos de; BASTOS, Rossano Lopes (Orgs.). Patrimônio 70 Anos. São Paulo: 90SR/Iphan, 2008. 352 p. 
Parque Ecológico Aldeia de Carapicuíba: Projeto de Paisagismo Participativo Valorizando um Patrimônio Histórico

MERLEAU-PONTY, M. Signos. São Paulo: Martins Fontes, 1991, p. 39-88.

OLIVEIRA, Marilza de. Para a história social da língua portuguesa em São Paulo: séculos XVI-XVIII. Disponível em: <http://dlcv.fflch.usp.br/sites/dlcv.fflch.usp.br/files/maril01 1.pdf>. Acesso em: 20 mai. 2016.

ZAHN, Carlos Eduardo; FEITOSA, Maria José; SAWAYA, Sylvio Barros. Aldeia de Carapicuíba: estudo histórico, arquitetônico e urbanístico do único aldeamento jesú́tico paulista remanescente. ECCOS, $n^{\circ} 1$, vol. 2. São Paulo: Centro Universitário Nove de Julho, 2000, p.135-141.

Nota do editor

Submissão: 8 ago. 2015

Aprovação: 29 fev. 2016 